\title{
Carbon arc production of heptagon-containing fullerene[68]
}

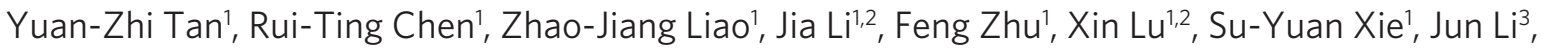
Rong-Bin Huang' \& Lan-Sun Zheng ${ }^{1}$

A carbon heptagon ring is a key unit responsible for structural defects in $\mathrm{sp}^{2}$-hybrized carbon allotropes including fullerenes, carbon nanotubes and graphenes, with consequential influences on their mechanical, electronic and magnetic properties. Previous evidence concerning the existence of heptagons in fullerenes has been obtained only in off-line halogenation experiments through top-down detachment of a $\mathrm{C}_{2}$ unit from a stable fullerene. Here we report a heptagonincorporating fullerene $\mathrm{C}_{68}$, tentatively named as heptafullerene[68], which is captured as $\mathrm{C}_{68} \mathrm{Cl}_{6}$ from a carbon arc plasma in situ. The occurrence of heptagons in fullerenes is rationalized by heptagon-related strain relief and temperature-dependent stability. ${ }^{13} \mathrm{C}$-labelled experiments and mass/energy conservation equation simulations show that heptafullerene[68] grows together with other fullerenes in a bottom-up fashion in the arc zone. This work extends fullerene research into numerous topologically possible, heptagon-incorporating isomers and provides clues to an understanding of the heptagon-involved growth mechanism and heptagondependent properties of fullerenes.

\footnotetext{
State Key Laboratory of Physical Chemistry of Solid Surfaces and Department of Chemistry, College of Chemistry and Chemical Engineering, Xiamen University, Xiamen 361005, China. ${ }^{2}$ Fujian Provincial Key Laboratory of Theoretical and Computational Chemistry, Xiamen University, Xiamen 361005 , China. ${ }^{3}$ Department of Chemical Engineering, College of Chemistry and Chemical Engineering, Xiamen University, Xiamen 361005, China. Correspondence and requests for materials should be addressed to S.Y.X. (email: syxie@xmu.edu.cn) or to Jun Li (email: junnyxm@xmu.edu.cn).
} 
C age-closed all-carbon structures, including fullerenes and carbon nanotubes, are typically composed of hexagon and pentagon carbon rings $s^{1,2}$. Experimentally, however, heptagon rings are also incorporated into carbon frameworks making the experimentally available carbon allotropes (for example, fullerenes and carbon nanotubes, as well as graphenes) defective species ${ }^{3-10}$. Although unambiguous identification of heptagons in the family of all-carbon allotropes remains an open question, numerous theoretic studies have focused on the heptagon-involved defect because of its key responsibility for changing geometric structures and properties of the experimentally available carbon allotropes ${ }^{11-19}$.

The possible existence of heptagons in carbon nanotubes was first proposed by Iijima ${ }^{3}$ in 1992 . A heptagon-incorporating fullerene, named a heptafullerene in this work, was originally proposed by Taylor ${ }^{20}$. Heptafullerene[72], which has been predicted by Akasaka and Nagase $^{21}$ from 431,240 isomeric possibilities, is more stable than the Isolated Pentagon Rule ${ }^{22}$ satisfying isomer in form of endofullerene Ca@ $\mathrm{C}_{72}$. A bare heptafullerene[62] with $\mathrm{C}_{\mathrm{s}}$-symmetry ${ }^{23}$, as well as the exohedral heptagon-containing $\mathrm{C}_{68} \mathrm{X}_{4}(\mathrm{X}=\mathrm{H}, \mathrm{F}, \mathrm{Cl})^{24}$, has been calculated to be more stable than all the classical nonheptagon isomers. Very recently, a number of smaller heptafullerenes $\left(\mathrm{C}_{46}-\mathrm{C}_{58}\right)$ have also been suggested to be viable ${ }^{18,25,26}$. However, experimental confirmation of the existence of heptagons in the family of fullerenes is still a challenge for chemists and physicists.

It is possible chemically to manipulate a few of the carbons on a fullerene surface to modify the carbon cages into heptafullerene derivatives, such as $\mathrm{C}_{58} \mathrm{~F}_{18}$ (ref. 27) and $\mathrm{C}_{84} \mathrm{Cl}_{32}$ (ref. 28). Such work has provided a breakthrough in the synthesis of heptafullerene derivatives by a top-down chemical method. Clearly, such synthetically produced halides of heptafullerenes $\left(\mathrm{C}_{58}\right.$ and $\left.\mathrm{C}_{84}\right)$ are not species directly retrieved from an in situ carbon-clustering process. Thus, these species do not establish the finite existence of unmodified heptafullerenes.

Here we perform an experiment, using graphite arc-discharge, which is well known for bottom-up growth of the whole family of $\mathrm{sp}^{2}$-hybrided carbon allotropes ${ }^{2,29,30}$, to capture a heptafullerene[68] in situ as a heptagon-containing $\mathrm{C}_{68} \mathrm{Cl}_{6}$ (hepta- $\mathrm{C}_{68} \mathrm{Cl}_{6}$ ).

\section{Results}

Carbon arc production and purification. $\mathrm{C}_{68} \mathrm{Cl}_{6}$ was produced in a Krätschmer-Huffman reactor of a graphite arc-discharge under $0.0395 \mathrm{~atm} \mathrm{CCl}_{4}$ and $0.1974 \mathrm{~atm}$ helium ${ }^{29,31}$. After separation and purification by multistage high performance liquid chromatography (HPLC), $1.6 \mathrm{mg}$ of the $\mathrm{C}_{68} \mathrm{Cl}_{6}$ of $99 \%$ purity was obtained from $150 \mathrm{~g}$ soot products of the $\mathrm{CCl}_{4}$-involving graphite arc-discharge (Methods; Supplementary Figs S1-S3).

Crystallographic structure. Single, black crystals suitable for Xray diffraction were grown by solvent evaporation of a mixed solution of carbon disulfide and chloroform (2:1 in volume) of $\mathrm{C}_{68} \mathrm{Cl}_{6}$, (Supplementary Figs S4 and S5; Supplementary Tables S1-S6 and Supplementary Methods). The molecular structure of $\mathrm{C}_{68} \mathrm{Cl}_{6}$ revealed by X-ray crystallography is shown in Figure 1. It has 22 hexagons, 13 pentagons and 1 heptagon on the surface of the molecular cage. Of these, four pentagons are contiguous to form two pairs of doubly fused pentagons, in which the carbon atoms at the fusion are bonded to chlorine to relieve the unfavourable local strain. As well as the four chlorine atoms associated with these pentagon fusions, two further chlorines are bonded, one at each of two pentagon-hexagon-hexagon vertexes. The resultant $\mathrm{sp}^{2}$-hybridized 62 -atom open-cage cluster is in good accord with the so-called Local aromaticity principle ${ }^{32}$.

Mass spectrometric analysis. The molecular composition of $\mathrm{C}_{68} \mathrm{Cl}_{6}$ is confirmed by mass spectrometry (MS) (Supplementary Fig. S3). Multistage mass spectrometric experiments show progressive dechlorination of $\mathrm{C}_{68} \mathrm{Cl}_{6}$ and the eventual formation of bare $\mathrm{C}_{68}$,

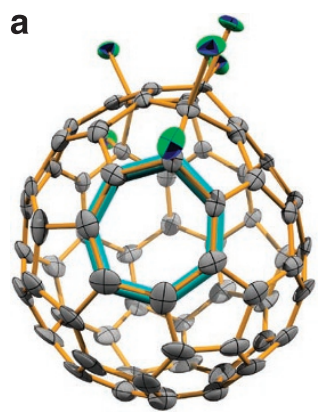

b

Figure 1 | Structure of $\mathbf{C}_{68} \mathbf{C l}_{6}$ molecule. ORTEP structure (a) and Schlegel diagram (b) of $\mathrm{C}_{68} \mathrm{Cl}_{6}$ (ORTEP = Oak ridge thermal ellipsoid plot).

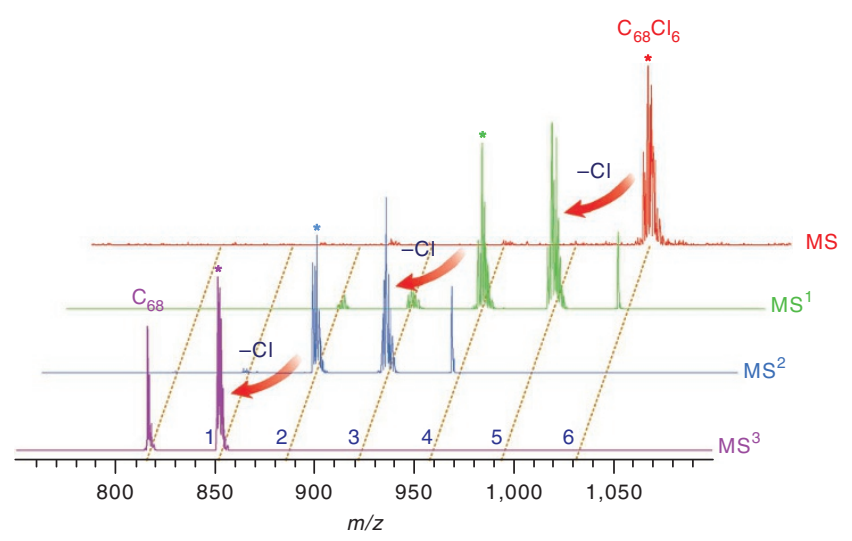

Figure 2 | Multistage mass spectrometry. $\left(M^{n}, n=1-3\right)$. Progressive dechlorination produces $\mathrm{C}_{68} \mathrm{Cl}_{m}(\mathrm{~m}=0-6)$ ( $\mathrm{m}$ is indicated in blue). The species picked for next stage of fragmentation, by collision with helium buffer gas in ion trap, is marked by an asterisk. $\mathrm{m} / \mathrm{z}$, mass to charge ratio.

with the implication that heptafullerene[68] itself has a finite lifetime in the gas phase (Fig. 2).

${ }^{13} \mathrm{C}$-Labelling experiments. To establish that the retrieved $\mathrm{C}_{68}$ species indeed grows together with other fullerenes in the $\mathrm{CCl}_{4}$-involving graphite arc-discharge conditions, a series of ${ }^{13} \mathrm{C}$-labelled experiments were conducted in a glass chamber (inner diameter (I.D.) $194 \mathrm{~mm}$ ) with reactants (graphite and $\mathrm{CCl}_{4}$ ) having different ${ }^{13} \mathrm{C}$ contents: (A) Exp. A with normal graphite and $\mathrm{CCl}_{4}$ (about $1.1 \mathrm{~atm}$ $\%{ }^{13} \mathrm{C}$ ); (B) Exp. B with 1.1 atm $\%{ }^{13} \mathrm{C}$ graphite and 99 atm $\%{ }^{13} \mathrm{CCl}_{4}$; (C) Exp. C with 21.8 atm $\%{ }^{13} \mathrm{C}$-rich graphite and $1.1 \mathrm{~atm} \%{ }^{13} \mathrm{CCl}_{4}$. The products were analysed by HPLC-MS technology to record the mass spectra for individual components (Supplementary Figs S6-S11). A total of 13 chlorinated polycyclic aromatic hydrocarbons (chloro-PAHs), 6 bare fullerenes, and 7 chlorofullerenes were detected in the crude products of the ${ }^{13} \mathrm{C}$-labelled experiments (Supplementary Figs S6-S11; Supplementary Table S7). Note that more species were detected when crude products were preliminarily concentrated by HPLC). Typical mass spectra of some selected products are shown in Figure 3, including smaller chloro-PAHs $\left(\mathrm{C}_{12} \mathrm{Cl}_{8}, \mathrm{C}_{18} \mathrm{Cl}_{10}\right.$ (isomer 2) and $\mathrm{C}_{20} \mathrm{Cl}_{10}$ (isomer 1)), typical fullerenes $\left({ }^{\# 1812} \mathrm{C}_{60}\right.$, ${ }^{\# 8149} \mathrm{C}_{70}$ and $\left.{ }^{\# 19150} \mathrm{C}_{76}\right)$, and chlorofullerenes $\left({ }^{\# 1809} \mathrm{C}_{60} \mathrm{Cl}_{8},{ }^{\# 271} \mathrm{C}_{50} \mathrm{Cl}_{10}\right.$ and hepta- $\mathrm{C}_{68} \mathrm{Cl}_{6}$ ). Note that the nomenclature specified by the Fowler-Manolopoulos spiral algorithm ${ }^{33}$ has been used to distinguish classical non-heptagonal isomers. The mass spectrum of each product clearly shows the featured mass-to-charge $(\mathrm{m} / \mathrm{z})$ pattern (Fig. 3; Supplementary Figs S6-S11). The $m / z$ pattern can be clearly defined by the isotopic ${ }^{12} \mathrm{C} /{ }^{13} \mathrm{C}$ content of the corresponding cluster (Supplementary Methods for details) and thus reflects the footprint 
of the parental carbon sources involved. Table 1 lists the estimated ${ }^{13} \mathrm{C}$ percentage of the selected carbon clusters according to the corresponding mass spectra recorded.

\section{Discussion}

A classical cage-closed all-carbon structure (fullerene or carbon nanotube) typically contains a number of hexagons and exactly 12 pentagons. However, because of the incorporation of a heptagon, the number of pentagons in the present $\mathrm{C}_{68}$ is increased to 13 . Two pairs of them are adjacent, in violation of the isolated pentagon rule ${ }^{22}$, rendering the bare $\mathrm{C}_{68}$ highly reactive and elusive. As a result of passivization by six chlorine atoms for the most reactive carbon

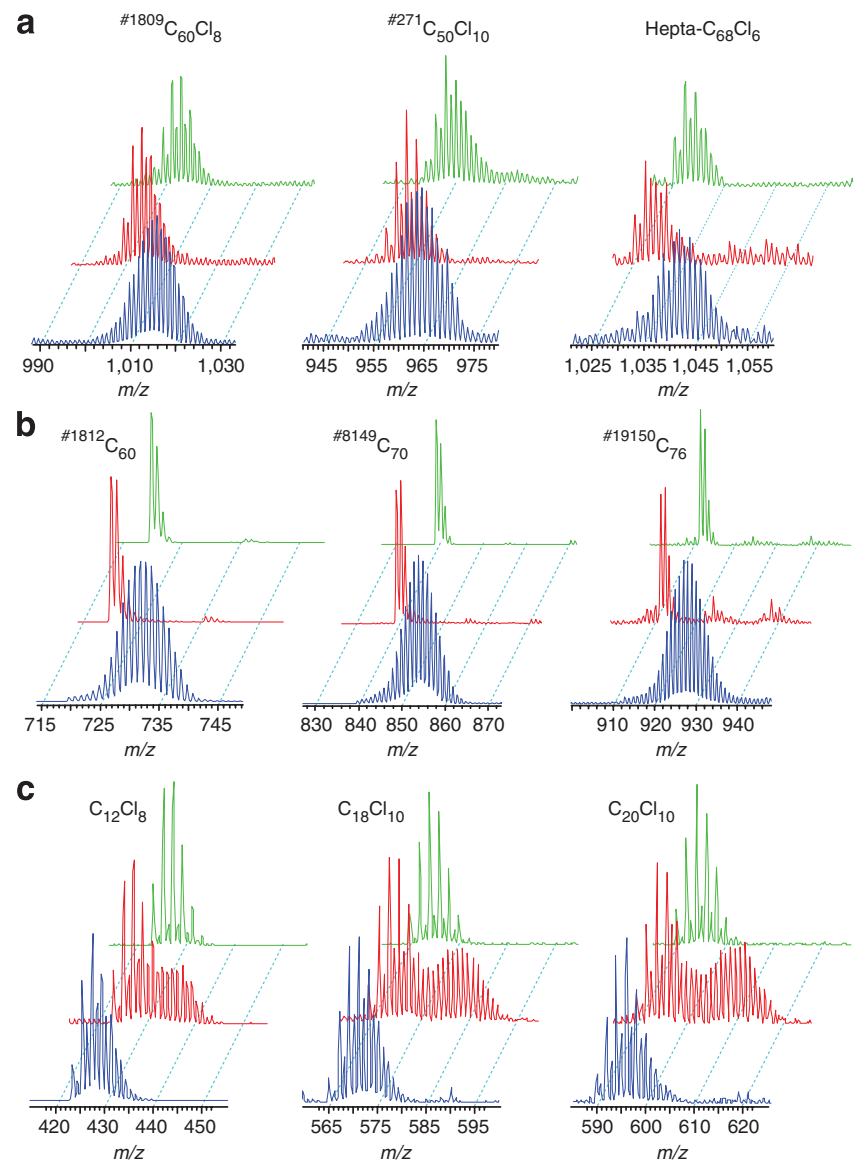

Figure 3 | Mass spectra of representative products from the ${ }^{13} \mathrm{C}$-labelled experiments. The products are exemplified by (a) chlorofullerenes ( ${ }^{\# 1809} \mathrm{C}_{60} \mathrm{Cl}_{8},{ }^{\# 271} \mathrm{C}_{50} \mathrm{Cl}_{10}$ and hepta- $\mathrm{C}_{68} \mathrm{Cl}_{6}$ ), (b) fullerenes $\left({ }^{\# 1812} \mathrm{C}_{60},{ }^{\# 8149} \mathrm{C}_{70}\right.$ and ${ }^{\# 19150} \mathrm{C}_{76}$ ) and (c) chloro-PAHs $\left[\mathrm{C}_{12} \mathrm{Cl}_{8}, \mathrm{C}_{18} \mathrm{Cl}_{10}\right.$ (2) and $\mathrm{C}_{20} \mathrm{Cl}_{10}$ (1)]. Spectra are coloured green, red and blue for Expts. (A), (B) and (C), respectively. $m / z$, mass to charge ratio. atoms at the pentagon fusions and the aromaticity-unsatisfied sites, the elusive $\mathrm{C}_{68}$ has been stabilized as chlorofullerene $\mathrm{C}_{68} \mathrm{Cl}_{6}$.

The most prominent feature in the captured $\mathrm{C}_{68}$ is the occurrence of a heptagon, which represents a new type of building unit for constructing cage-closed all-carbon architectures. In contrast to previously reported non-heptagonal fullerenes, heptafullerene[68] contains a heptagon having about $10 \%$ more space than a hexagon, and this presumably delivers easier pass through of foreign atoms, such as helium or nitrogen, to produce endofullerenes for potential technical applications. Indeed, first-principle density functional theory (DFT) calculations (Supplementary Fig. S12; Supplementary Table S10 and Supplementary Methods) predict that the activation energy for a helium atom penetrating into a fullerene cage decreases dramatically from $225.1 \mathrm{kcal} \mathrm{mol}^{-1}$ for $\mathrm{I}_{\mathrm{h}}-\mathrm{C}_{60}$ to $128.4 \mathrm{kcal} \mathrm{mol}^{-1}$ for hepta- $\mathrm{C}_{68} \mathrm{Cl}_{6}$. This easier penetration of helium into hepta- $\mathrm{C}_{68} \mathrm{Cl}_{6}$ is also supported by mass spectrometric evidence (Supplementary Fig. S13). The heptagon is surrounded by four pentagons and three hexagons. One of the carbon atoms in the heptagon is shared by two adjacent pentagons and subsequently transformed from $\mathrm{sp}^{2}$ - to $\mathrm{sp}^{3}$-hybridization to release the strain of the doubly fused pentagons. Of interest is the decreased $\pi$-orbital axis vector (POAV) angle ${ }^{34}$ of $6.0-10.4^{\circ}$ (average $8.2^{\circ}$ ) at the fusions of the remaining two pairs of $\mathrm{sp}^{2}$-hybridized pentagon-heptagon junctions (Fig. 1b). These POAV angles are even smaller than those in the stable buckminsterfullerene $I_{\mathrm{h}}-\mathrm{C}_{60}\left(11.64^{\circ}\right)$, rendering heptafullerene[68] a heptagon-related planarity. Such kinds of decreased POAV angle have also been seen in the recently reported $\mathrm{C}_{84} \mathrm{Cl}_{32}$ molecule, in which the POAV angles at the carbon atoms of the heptagon are in the range of $3.2-5.8^{\circ}$ (average $\left.5.2^{\circ}\right)^{28}$. As the heptagon-related planarity facilitates strain relief in a curved surface of a cage, the existence of a heptagon may be expected to bring extra stabilization for the carbon cage involved. However, DFT calculations reveal substantial accommodation of the highest occupied molecular orbital electron densities around the cycloheptatrienelike ring of hepta- $\mathrm{C}_{68} \mathrm{Cl}_{6}$ (Supplementary Fig. S14; Supplementary Table S11 and Supplementary Methods), implying a readiness for electrophilic additions at the heptagon area. DFT calculations also suggest that the $\mathrm{C}-\mathrm{Cl}$ bond pertaining to the cycloheptatriene-like ring of hepta- $\mathrm{C}_{68} \mathrm{Cl}_{6}$ is subject to nucleophilic substitution by taking advantage of local aromaticity of the 6 -electron $\pi$-conjugated $\mathrm{C}_{7}{ }^{+}$ tropylium-like ring in the corresponding hepta- $\mathrm{C}_{68} \mathrm{Cl}_{5}{ }^{+}$intermediate (Supplementary Fig. S15; Supplementary Table S12 and Supplementary Methods). Thus, the cycloheptatriene-like ring of hepta- $\mathrm{C}_{68} \mathrm{Cl}_{6}$ is a double-edged sword, conveying unique reactivity to this heptagon-incorporating fullerene derivative, making it subject to both electrophilic addition and nucleophilic substitution.

Theoretical studies predict that the hepta- $\mathrm{C}_{68}$ has an energy comparable to that of the most stable isomers of classical $\mathrm{C}_{68}$ that lack a heptagon. At room temperature, the hepta- $\mathrm{C}_{68}$ is the third most stable of the $\mathrm{C}_{68}$ isomers, with an energy $\sim 2.5 \mathrm{kcal} \mathrm{mol}^{-1}$ higher than the most stable one. At a temperature above $2,100 \mathrm{~K}$, however, the heptagon-incorporating $\mathrm{C}_{68}$ becomes the most abundant species as entropic factors have a decisive role in their relative Gibbs free energies and relative concentrations/abundances (Supplementary

Table 1 | The ${ }^{13} \mathrm{C}$ percentage estimated from mass spectra of selected carbon clusters produced in ${ }^{13} \mathrm{C}$-labelled experiments.

\begin{tabular}{|c|c|c|c|c|c|c|c|c|c|}
\hline \multirow[t]{2}{*}{ Exp. series } & \multicolumn{3}{|c|}{ Chloro-PAHs $^{\star}$} & \multicolumn{3}{|c|}{ Fullerenes } & \multicolumn{3}{|c|}{ Chlorofullerenes } \\
\hline & $\mathrm{C}_{12} \mathrm{Cl}_{8}$ & $\mathrm{C}_{18} \mathrm{Cl}_{10}(2)$ & $\mathrm{C}_{20} \mathrm{Cl}_{10}(1)$ & $\# 1812 \mathrm{C}_{60}$ & ${ }^{\# 1499} \mathrm{C}_{70}$ & $\# 19150 \mathrm{C}_{76}$ & $\# 1809 \mathrm{C}_{60} \mathrm{Cl}_{8}$ & $\# 271 \mathrm{C}_{50} \mathrm{Cl}_{10}$ & Hepta- $\mathrm{C}_{68} \mathrm{Cl}_{6}$ \\
\hline Exp. A & $1.10 \pm 0.02$ & $1.09 \pm 0.02$ & $1.11 \pm 0.02$ & $1.10 \pm 0.02$ & $1.10 \pm 0.02$ & $1.10 \pm 0.02$ & $1.09 \pm 0.02$ & $1.10 \pm 0.02$ & $1.09 \pm 0.02$ \\
\hline Exp. C & $\begin{array}{r}4.8 \pm 0.4 \\
20.4 \pm 0.1\end{array}$ & $\begin{array}{r}5.2 \pm 0.4 \\
20.4 \pm 0.1\end{array}$ & $\begin{array}{r}5.1 \pm 0.4 \\
20.4 \pm 0.1\end{array}$ & $20.41 \pm 0.07$ & $20.37 \pm 0.07$ & $20.36 \pm 0.07$ & $20.40 \pm 0.07$ & $20.42 \pm 0.07$ & $20.44 \pm 0.07$ \\
\hline
\end{tabular}

*Limited by the precision to distinguish the combined mass spectra, only one decimal digit of the ${ }^{13} \mathrm{C}$ percentage was evaluated for chloro-PAHs in Expts B and C. 
Tables S8 and S9). In agreement with this prediction about the temperature-dependent stability, several theoretical studies have suggested the prevalence of heptagons in the world of the cageclosed all-carbon allotropes ${ }^{11-21,23-26,35,36}$. Experimental corroboration of such a prevalence of heptagons heavily depends on the in situ capture of heptafullerene in the carbon clustering venue for the growth of the whole family of fullerenes. However, the previously reported heptafullerene derivatives (hepta- $\mathrm{C}_{58} \mathrm{~F}_{18}$ and hepta- $\mathrm{C}_{84} \mathrm{Cl}_{32}$ ) were synthesized by an off-line top-down method through chemical detachment of a $\mathrm{C}_{2}$ unit from a stable fullerene $\left(\mathrm{C}_{60} \text { or } \mathrm{C}_{86}\right)^{27,28}$. This top-down approach is similar to the so-called open-cage method in which the hexagons/pentagons of fullerene cages (typically $\mathrm{C}_{60}$ ) are modified to give so-called open-cage fullerenes containing rings with twelve-, sixteen-, or eighteen-membered-rings and beyond ${ }^{37-39}$. By fluorination of $\mathrm{C}_{60}$ at $550^{\circ} \mathrm{C}$, therefore, it is not surprising that two carbon atoms at a hexagon-pentagon fusion of $\mathrm{C}_{60}$ have been removed to form stable derivatives of heptafullerene[58], $\mathrm{C}_{58} \mathrm{~F}_{18}$ or $\mathrm{C}_{58} \mathrm{~F}_{17} \mathrm{CF}_{3}$ (ref. 27). Very recently, the chlorinated heptafullerene[84] $\mathrm{C}_{84} \mathrm{Cl}_{32}$ has also been synthesized from $\mathrm{C}_{86}$ by chlorination at $250^{\circ} \mathrm{C}$ (ref. 28). These cases, however, are inappropriate for establishing the survival of bare heptafullerenes in a bottom-up clustering process during growth of the whole fullerene family.

In contrast, the present heptafullerene[68] molecule was captured in situ and directly isolated from the pristine products of a carbon arc, which is a typical venue for bottom-up growth of carbon allotropes such as fullerenes ${ }^{29}$, carbon nanotubes ${ }^{2}$ and graphenes ${ }^{30}$. Powerful evidence to establish the bottom-up process comes from the ${ }^{13} \mathrm{C}$-labelled Exp. C: the reactant of $21.8 \mathrm{~atm} \%{ }^{13} \mathrm{C}$-rich graphite is an inhomogeneous mixture with a $90 \mathrm{~atm} \%{ }^{13} \mathrm{C}$-rich carbon powder filled into a hollow graphite rod with regular $1.1 \mathrm{~atm} \%$ ${ }^{13} \mathrm{C}$ content (Methods), but the produced hepta- $\mathrm{C}_{68} \mathrm{Cl}_{6}$ and other fullerene species (for example, ${ }^{\# 1812} \mathrm{C}_{60},{ }^{\# 8149} \mathrm{C}_{70},{ }^{\# 19150} \mathrm{C}_{76},{ }^{\# 1809} \mathrm{C}_{60} \mathrm{Cl}_{8}$, and ${ }^{\# 271} \mathrm{C}_{50} \mathrm{Cl}_{10}$ ) show an almost homogeneous ${ }^{13} \mathrm{C}$ percentage of 20.4 atm \% (rather than the separated 1.1 or 90 atm \% value) in the corresponding mass spectra (Fig. 3; Supplementary Figs S9 and S10). This evidence, in accordance with previous literature $e^{40-42}$, clearly confirms that fullerenes grow from atomization of a carbon or small carbon clusters such as $\mathrm{C}_{2}$ derived from graphite in the carbon arc process. Moreover, our ${ }^{13} \mathrm{C}$-labelled experiments also ascertain that the bare heptafullerene[68] grows together with other fullerenes in the arc zone at high temperature and subsequently is captured by chlorine atoms produced from $\mathrm{CCl}_{4}$ in the carbon arc conditions.

In the present $\mathrm{CCl}_{4}$-involving graphite arc-discharge conditions, there are two carbon sources for the growth of carbon clusters, that is, the reactive carbon species from graphite (C-source I) and $\mathrm{CCl}_{4}$ (C-source II). The former C-source I has a gradual density distribution with enhanced concentration at the arc zone but decreased beyond, whereas the latter $\mathrm{CCl}_{4}$ source II is assumed to disperse in association with temperature distribution in the reaction chamber. The density of C-source I (or II) versus the distance from the arc centre (that is, the radius) in the reactor can be simulated based on mass conservation equation (Supplementary Figs S16-S20; Supplementary Tables S13, S14 and Supplementary Methods). Accordingly, the carbon clusters produced at a certain region in the reactor can be quantified to grow from a mixture of carbon sources with an exclusive proportion of C-source I versus C-source II. In the present ${ }^{13} \mathrm{C}$-labelled experiments, we conducted the syntheses of carbon clusters in a glass chamber (I.D. $194 \mathrm{~mm}$ ) starting with the graphite and $\mathrm{CCl}_{4}$ having different ${ }^{12} \mathrm{C} /{ }^{13} \mathrm{C}$ ratios, that is, Exp. A with normal graphite and $\mathrm{CCl}_{4}\left(1.1 \mathrm{~atm} \%{ }^{13} \mathrm{C}\right)$, Exp. B with 1.1 atm $\%{ }^{13} \mathrm{C}$ graphite and $99 \mathrm{~atm} \%{ }^{13} \mathrm{CCl}_{4}$, and Exp. C with 21.8 atm $\%{ }^{13} \mathrm{C}$-rich graphite and $1.1 \mathrm{~atm} \%{ }^{13} \mathrm{CCl}_{4}$. The products formed at a certain region inside the reactor would deliver an exclusive ${ }^{12} \mathrm{C} /{ }^{13} \mathrm{C}$ isotopic ratio that can be determined from the isotopic pattern recorded in the corresponding mass spectra (for example, Fig. 3). For example, the

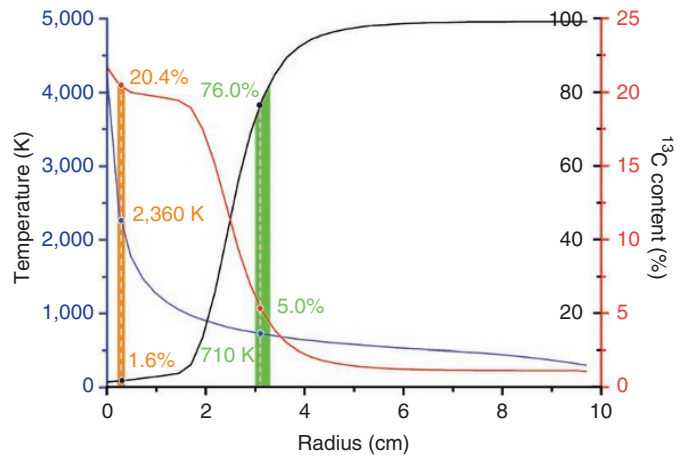

Figure 4 | Simulated curves of temperature and ${ }^{13} \mathrm{C}$ content. Simulated temperature (blue line) and ${ }^{13} \mathrm{C}$ content of carbon sources (black for Exp. B, red for Exp. C) versus distance from the arc centre (radius $r$ ) for a reaction period of $600 \mathrm{~s}$. Fullerenes with ${ }^{13} \mathrm{C}$ content of $1.6 \pm 0.1 \%$ in Exp. $B$ and $20.4 \pm 0.1 \%$ in Exp. $C$ are produced in an area of $r \sim 2-3 \mathrm{~mm}$ at $\sim 2,000-2,500 \mathrm{~K}$ (orange background) while a fraction of chloro-PAHs with ${ }^{13} \mathrm{C}$ content of $76.0 \pm 0.9 \%$ in Exp. B and $5.0 \pm 0.4 \%$ in Exp. $C$ are produced in an area of $r=\sim 30-33 \mathrm{~mm}$ at $\sim 700-730 \mathrm{~K}$ (green background).

mass spectrum of hepta- $\mathrm{C}_{68} \mathrm{Cl}_{6}$ itself shows the isotopic percentage of ${ }^{13} \mathrm{C}$ being $\sim 1.6 \%{ }^{13} \mathrm{C}$ in Exp. $\mathrm{B}$ and $\sim 20.4 \%{ }^{13} \mathrm{C}$ in Exp. C. Sequentially, the region for the growth of the carbon cluster product can be located simply according to the relationship of the ${ }^{13} \mathrm{C}$ isotopic percentage of products/reactants versus the location in the reactor for Exp. B or C (Supplementary Figs S6-11, S16-20; Supplementary Tables S7, S13, S14 and Supplementary Methods).

Figure 4 shows the simulated curves of ${ }^{13} \mathrm{C}$ content of reactive carbon sources (C-source I plus II) versus the distance from the arc centre in the reactor for Expts B and C (detailed calculations regarding mass conservation equation are described in Supplementary Methods). According to the simulated curves and the estimated ${ }^{13} \mathrm{C}$ content in the hepta- $\mathrm{C}_{68} \mathrm{Cl}_{6}$ produced from the ${ }^{13} \mathrm{C}$-labelled experiments (Expts B and C), it can be concluded that the carbon framework of hepta- $\mathrm{C}_{68} \mathrm{Cl}_{6}$ grows in the arc zone about $2-3 \mathrm{~mm}$ from the arc centre. Interestingly, as shown in the corresponding mass spectra (Fig. 3; Supplementary Figs S6, S7, S9 and S10), isotopic percentages of ${ }^{13} \mathrm{C}$ in other representative fullerene species (for example, ${ }^{\# 1812} \mathrm{C}_{60},{ }^{\# 8149} \mathrm{C}_{70},{ }^{\# 19150} \mathrm{C}_{76},{ }^{\# 1809} \mathrm{C}_{60} \mathrm{Cl}_{8}$, and ${ }^{\# 271} \mathrm{C}_{50} \mathrm{Cl}_{10}$ ) are approximately the same as those of hepta- $\mathrm{C}_{68} \mathrm{Cl}_{6}$ itself, that is, $\sim 1.1 \%{ }^{13} \mathrm{C}$ in Exp. $\mathrm{A}$, $\sim 1.6 \%{ }^{13} \mathrm{C}$ in Exp. B, and $\sim 20.4 \%{ }^{13} \mathrm{C}$ in Exp. C, implying that the heptafullerene[68] grows together with the other fullerenes in the same zone. Conformity of the reaction area with the experimentally obtained ${ }^{13} \mathrm{C}$ contents of fullerenes in both Exp. B and Exp. C validates the model of the mass conservation equation. Although the precision remains to be established, the proposed reaction zone might be informative for improving the yields of fullerenes in the carbon arc. As an example, we designed a synthetic experiment using a hollow anode (I.D. $4 \mathrm{~mm}$ ) to replace a solid anode under otherwise identical arc-discharge conditions. Very interestingly, the yields of fullerene species such as ${ }^{\# 1812} \mathrm{C}_{60},{ }^{\# 149} \mathrm{C}_{70}$ and ${ }^{\# 1809} \mathrm{C}_{60} \mathrm{Cl}_{8}$ were improved twofold (Supplementary Fig. S21 and Supplementary Methods), probably due to increase of the reaction venue at $\sim 2 \mathrm{~mm}$ from the arc centre.

The temperature for fullerene growth in a carbon arc is still uncertain. At the centre of the arc zone, the temperature could be higher than 4,000 K during the carbon-clustering process ${ }^{43}$. Beyond the arc zone, the temperature decreases rapidly. The relationship of temperature with the distance from the arc centre can also be simulated by an energy-conservation equation. The simulated temperature curve has been calibrated for good fit to the experimental data at sites of 34, 43 and $52 \mathrm{~mm}$ from the arc centre for a reaction time of 300 s (Supplementary Figs S17 and S18). Because fullerenes grow 


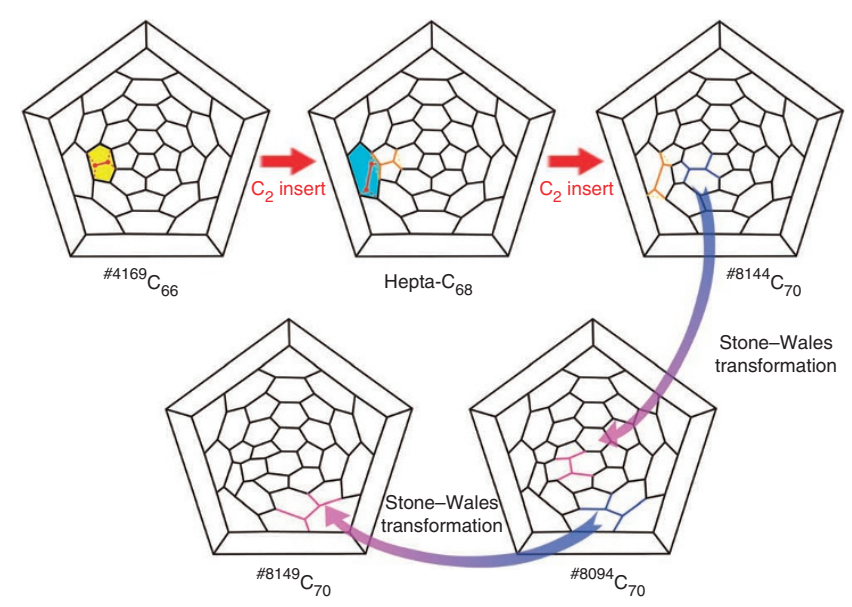

Figure 5 | Heptagon Road. Possible growth of fullerene from ${ }^{\# 4169} \mathrm{C}_{66}$ to ${ }^{\# 8149} \mathrm{C}_{70}$ through hepta- $\mathrm{C}_{68}$ by the Heptagon Road and two Stone-Wales transformations.

at a region $\sim 2$ to $3 \mathrm{~mm}$ from the arc centre, the temperature region for fullerene growth can be estimated to be about $2,000-2,500 \mathrm{~K}$ from the simulated temperature curve (Fig. 4). This estimate is in line with the above DFT prediction that hepta- $\mathrm{C}_{68}$ is the most abundant isomer at a temperature higher than 2,100 K (Supplementary Tables S8 and S9). It appears that at such a high temperature, $\mathrm{Cl}-\mathrm{C}$ bonds can not survive and are likely irrelevant to the formation of pristine fullerenes.

However, a drastic difference was observed in the mass spectra of smaller chlorinated carbon clusters, such as $\mathrm{C}_{12} \mathrm{Cl}_{8}, \mathrm{C}_{14} \mathrm{Cl}_{8}(1,2)$, $\mathrm{C}_{16} \mathrm{Cl}_{10}(1-3), \mathrm{C}_{18} \mathrm{Cl}_{10}(1,2)$ and $\mathrm{C}_{20} \mathrm{Cl}_{10}$ (1-3) (Fig. 3 and Table 1, as well as Supplementary Figs S8, S11 and Supplementary Table S7). These smaller carbon clusters should have open structures similar to PAHs, because a carbon cluster of less than twenty carbon atoms is too small to give a cage structure. The Exp. B data exemplify that the corresponding mass spectra of these chloro-PAHs (red mass spectra in Fig. 3; Supplementary Fig. S8), very different from those of fullerenes (Supplementary Figs S6 and S7), are a combination of two sets of $\mathrm{m} / \mathrm{z}$ signals assignable to ${ }^{13} \mathrm{C}$ abundance ratios of approximately $\sim 1.6$ and $\sim 76.0 \mathrm{~atm} \%{ }^{13} \mathrm{C}$-rich species. Scrutiny of the mass spectra of Exp. C distinguishes two kinds of ${ }^{13} \mathrm{C}$ percentage (average $\sim 5.0$ and $\sim 20.4$ atm \%) for the chloro-PAHs also (Supplementary Fig. S11). Accordingly, two kinds of smaller carbon cluster can be established as growing from different reactive sources: one is produced in the high-temperature zone together with fullerenes and the other is formed in a chlorine-involving process in the region about $30-33 \mathrm{~mm}$ from the arc centre at $\sim 700-730 \mathrm{~K}$ (Fig. 4 ). The latter result is in accord with the fact that the smaller chlorinated PAHs can be produced from $\mathrm{CCl}_{4}$ under pyrolysis conditions at around $600-1,000 \mathrm{~K}$ (refs 44, 45), and, therefore, differentiates it from the formation mechanism of fullerene species. Such a formation difference between fullerenes and chloro-PAHs also corroborates that the parent heptafullerene[68] and other fullerenes grow in the hightemperature zone, independently of chlorine, and subsequently are captured/stabilized by chlorine on cooling outside the arc zone. The survival of heptafullerene in the carbon clustering process is thus clarified.

On the basis of its crystallographic structure, the connectivity of hepta- $\mathrm{C}_{68}$ also supports a hitherto unidentified mechanism for fullerene growth, namely the Heptagon road, in which the insertion of a $\mathrm{C}_{2}$ cluster and the generation of heptafullerene have been suggested ${ }^{46}$. In the same carbon arc process, we have also been able to capture and isolate ${ }^{\# 4169} \mathrm{C}_{66}$ and ${ }^{\# 149} \mathrm{C}_{70}$ (ref. 47). From a structural point of view, these two carbon clusters might be possible preceding/ subsequent intermediates bridged by the heptafullerene[68]. The scheme shown in Figure 5 suggests a possible route for the formation of ${ }^{\# 149} \mathrm{C}_{70}$ by the Heptagon road involving $\mathrm{C}_{2}$-insertion growth from ${ }^{\# 4169} \mathrm{C}_{66}$ to ${ }^{\# 1144} \mathrm{C}_{70}$, as well as two Stone-Wales transformations from ${ }^{\# 8144} \mathrm{C}_{70}$ to ${ }^{\# 8149} \mathrm{C}_{70}$. It should be noted that this is just a possible implication simply inferred from the structures. Powerful evidence to elucidate the authentic mechanism is needed and further theoretical and experimental studies are now in hand.

In summary, heptafullerene[68] has been made and captured as chlorinated derivatives in a $\mathrm{CCl}_{4}$-involving graphite arc-discharge process. The ${ }^{13} \mathrm{C}$-labelled synthetic experiments and mass/energy conservation equation simulations reveal that bare heptafullerene can grow in a bottom-up fashion in the arc zone at high temperature and survive in the gas phase during the carbon clustering process. This work, supported by X-ray crystallographic data and theoretical computations, fundamentally establishes that heptagon-incorporating fullerenes should not have been excluded in the classical fullerene family. It thus greatly increases the numbers of members of the fullerene family. The discovery of heptafullerene[68] may be expected to stimulate research activity in the field of all-carbon allotropes involving heptagons, for example: the synthesis of more heptagon-incorporating members in the family of carbon cages, understanding the formation mechanism(s) involving heptagons, and investigations of heptagon-dependent properties of carbon allotropes.

\section{Methods}

Carbon arc production. The carbonaceous soot containing fullerenes, chlorofullerenes, and smaller carbon clusters was produced under $0.1974 \mathrm{~atm} \mathrm{He}$ and $0.0395 \mathrm{~atm} \mathrm{CCl}_{4}$ in a Krätschmer-Huffman arc-discharge reactor ${ }^{29,31}$, equipped with two graphite electrodes, a cathode cylinder block [ $40 \mathrm{~mm}$ (diameter) $\times 60 \mathrm{~mm}$ ] and an anode rod [ $8 \mathrm{~mm}$ diameter $\times 300 \mathrm{~mm}$ ]. An hourly production of about $3 \mathrm{~g}$ of soot was achieved for a power input of $33 \mathrm{~V}$ and $100 \mathrm{~A}$

${ }^{13} \mathrm{C}$-labelled experiments. The ${ }^{13} \mathrm{C}$-labelled synthetic experiments were conducted in a glass chamber (I.D. $194 \mathrm{~mm})$ starting with reactants $\left(\mathrm{CCl}_{4}\right.$ and graphite anode, diameter of $6 \mathrm{~mm}$ ) having different ${ }^{13} \mathrm{C}$ contents. Exp. A was conducted with normal graphite and $\mathrm{CCl}_{4}$ having the same ${ }^{13} \mathrm{C}$ percentage (about $1.1 \mathrm{~atm} \%$ ), Exp. B with $1.1 \mathrm{~atm} \%{ }^{13} \mathrm{C}$ graphite and $99 \mathrm{~atm} \%{ }^{13} \mathrm{CCl}_{4}$, and Exp. C with $21.8 \mathrm{~atm} \%$ ${ }^{13} \mathrm{C}$-rich graphite and $1.1 \mathrm{~atm} \%{ }^{13} \mathrm{CCl}_{4}$. The ${ }^{13} \mathrm{C}$-rich graphite was prepared by filling 90 atm $\%{ }^{13} \mathrm{C}$-carbon powder into a regular $1.1 \mathrm{~atm} \%{ }^{13} \mathrm{C}$ hollow graphite rod.

Isolation and identification. Hepta- $\mathrm{C}_{68} \mathrm{Cl}_{6}$ was extracted by toluene in an ultrasonic bath from the carbonaceous soot and purified by multistage HPLC process sequentially using a pyrenebutyric acid bonded silica column (I.D. $20 \times 250 \mathrm{~mm}$ ) a Cosmosil Buckyprep column (I.D. $10 \times 250 \mathrm{~mm}$ ), and a 5PPB column (I.D. $10 \times 250 \mathrm{~mm}$ ). All preparative HPLC were performed on a Shimadzu LC-6AD HPLC instrument at rt using toluene as eluent. HPLC-MS for the products from the ${ }^{13} \mathrm{C}$-labelled synthetic experiments was analysed on a Discovery $\mathrm{C} 18$ column (I.D. $4.6 \times 250 \mathrm{~mm}$ ) of SUPELCO eluted by a methanol-ethanol-cyclohexane gradient. Mass spectra were recorded on a Bruker HCT mass instrument. Crystallographic data were collected on an Oxford CCD diffractometer (Supplementary Methods; Supplementary Data 1)

\section{References}

1. Kroto, H. W., Heath, J. R., O’Brien, S. C., Curl, R. F. \& Smalley, R. E. C60 buckminsterfullerene. Nature 318, 162-163 (1985).

2. Iijima, S. Helical microtubules of graphitic carbon. Nature 354, 56-58 (1991).

3. Ijima, S., Ishihashi, T. \& Ando, Y. Pentagons, heptagons and negative curvature in graphite microtubule growth. Nature 356, 776-778 (1992).

4. Britto, P. J., Santhanam, K. S. V., Rubio, A., Alonso, J. A. \& Ajayan, P. M. Improved charge transfer at carbon nanotube electrodes. Adv. Mater. 11 154-157 (1999)

5. Lahiri, J., Lin, Y., Bozkurt, P., Oleynik, I. I. \& Batzill, M. An extended defect in graphene as a metallic wire. Nat. Nanotechnol. 5, 326-329 (2010).

6. Hashimoto, A., Suenaga, K., Gloter, A., Urita, K. \& Iijima, S. Direct evidence for atomic defects in graphene layers. Nature 430, 870-873 (2004).

7. Suenaga, K. et al. Imaging active topological defects in carbon nanotubes. Nat. Nanotechnol. 2, 358-360 (2007).

8. Gomez-Navarro, C. et al. Atomic structure of reduced graphene oxide. Nano Lett. 10, 1144-1148 (2010).

9. Ouyang, M., Huang, J. L., Cheung, C. L. \& Lieber, C. M. Atomically resolved single-walled carbon nanotube intramolecular junctions. Science 291, 97-100 (2001). 
10. Fujimori, T., Urita, K., Ohba, T., Kanoh, H. \& Kaneko, K. Evidence of dynamic pentagon-heptagon pairs in single-wall carbon nanotubes using surfaceenhanced raman scattering. J. Am. Chem. Soc. 132, 6764-6767 (2010).

11. Grantab, R., Shenoy, V. B. \& Ruoff, R. S. Anomalous strength characteristics of tilt grain boundaries in graphene. Science 330, 946-948 (2010).

12. Yazyev, O. V. \& Louie, S. G. Electronic transport in polycrystalline graphene. Nature Mater. 9, 806-809 (2010).

13. Lopez-Sancho, M. P., de Juan, F. \& Vozmediano, M. A. H. Magnetic moments in the presence of topological defects in graphene. Phys. Rev. B 79, 075413/075411-075413/075415 (2009).

14. Jeong, B. W., Ihm, J. \& Lee, G.- D. Stability of dislocation defect with two pentagon-heptagon pairs in graphene. Phys. Rev. B 78, 165403/165401165403/165405 (2008).

15. Botello-Mendez, A. R. et al. Spin polarized conductance in hybrid graphene nanoribbons using 5-7 defects. ACS Nano 3, 3606-3612 (2009).

16. Charlier, J. C. Defects in carbon nanotubes. Acc. Chem. Res. 35, 1063-1069 (2002).

17. Milosevic, I., Popovic, Z., Volonakis, G., Logothetidis, S. \& Damnjanovic, M Electromechanical switch based on pentaheptite nanotubes. Phys. Rev. B 76, 115406/115401-115406/115405 (2007).

18. Chen, D. L., Tian, W. Q., Feng, J. K. \& Sun, C. C. Structures, stabilities, and electronic and optical properties of $\mathrm{C}_{58}$ fullerene isomers, ions, and metallofullerenes. ChemPhysChem 8, 1029-1036 (2007).

19. Bates, K. R. \& Scuseria, G. E. Why are buckyonions round? Theor. Chem. Acc. 99, 29-33 (1998)

20. Taylor, R. The third form of carbon: a new era in chemistry. Interdiscip. Sci. Rev. 17, 161-170 (1992).

21. Akasaka, T. \& Nagase, S. Endofullerenes: a New Family of Carbon Clusters (Kluwer Academic, 2002).

22. Kroto, H. W. The stability of the fullerenes $C_{n}$, with $n=24,28,32,36,50,60$ and 70. Nature 329, 529-531 (1986).

23. Ayuela, A. et al. $\mathrm{C}_{62}$ : theoretical evidence for a nonclassical fullerene with a heptagonal ring. J. Phys. Chem. 100, 15634-15636 (1996).

24. Xu, L., Shao, X. \& Cai, W. Electronic structures, stabilities, and spectroscopies of the fullerene derivatives $\mathrm{C}_{68} \mathrm{X}_{4}(\mathrm{X}=\mathrm{H}, \mathrm{F}, \mathrm{Cl})$. Theochem. 945, 33-38 (2010).

25. Gan, L. H., Zhao, J. Q. \& Hui, Q. Nonclassical fullerenes with a heptagon violating the pentagon adjacency penalty rule. J. Comput. Chem. 31, 1715-1721 (2010).

26. Gan, L. H. et al. Geometrical and electronic rules in fullerene-based compounds. Chem. -Asian J. 6, 1304-1314 (2011).

27. Troshin, P. A. et al. Isolation of two seven-membered ring $\mathrm{C}_{58}$ fullerene derivatives: $\mathrm{C}_{58} \mathrm{~F}_{17} \mathrm{CF}_{3}$ and $\mathrm{C}_{58} \mathrm{~F}_{18}$. Science 309, 278-281 (2005).

28. Ioffe, I. N. et al. Chlorination of $\mathrm{C}_{86}$ to $\mathrm{C}_{84} \mathrm{Cl}_{32}$ with nonclassical heptagoncontaining fullerene cage formed by cage shrinkage. Angew. Chem. Int. Ed. 49, 4784-4787 (2010)

29. Kratschmer, W., Lamb, L. D., Fostiropoulos, K. \& Huffman, D. R. Solid C60 a new form of carbon. Nature 347, 354-358 (1990).

30. Wu, Z. S. et al. Synthesis of graphene sheets with high electrical conductivity and good thermal stability by hydrogen arc discharge exfoliation. ACS Nano 3, 411-417 (2009).

31. Gao, F., Xie, S. Y., Huang, R. B. \& Zheng, L. S. Significant promotional effect of $\mathrm{CCl}_{4}$ on fullerene yield in the graphite arc-discharge reaction. Chem. Commun 2676-2677 (2003)

32. Tan, Y. Z., Xie, S. Y., Huang, R. B. \& Zheng, L. S. The stabilization of fusedpentagon fullerene molecules. Nat. Chem. 1, 450-460 (2009).

33. Fowler, P. W. \& Manolopoulos, D. E. An Atlas of Fullerenes (Oxford University Press, Oxford, 1995).

34. Haddon, R. C. $\pi$-Electrons in three dimensiona. Acc. Chem. Res. 21, 243-249 (1988).

35. Zhao, J. Q. \& Gan, L. H. Structures and stability of the hydrides of $\mathrm{C}_{32}, \mathrm{C}_{34}$ and $\mathrm{C}_{36}$. Chem. Phys. Lett. 464, 73-76 (2008).
36. An, J., Gan, L. H., Zhao, J. Q. \& Li, R. A global search for the lowest energy isomer of $\mathrm{C}_{26}$. J. Chem. Phys. 132, 154304/154301-154304/154307 (2010).

37. Komatsu, K., Murata, M. \& Murata, Y. Encapsulation of molecular hydrogen in fullerene $\mathrm{C}_{60}$ by organic synthesis. Science 307, 238-240 (2005).

38. Vougioukalakis, G. C., Roubelakis, M. M. \& Orfanopoulos, M. Open-cage fullerenes: towards the construction of nanosized molecular containers. Chem. Soc. Rev. 39, 817-844 (2010).

39. Gan, L., Yang, D., Zhang, Q. \& Huang, H. Preparation of open-cage fullerenes and incorporation of small molecules through their orifices. Adv. Mater. 22, 1498-1507 (2010).

40. Yannoni, C. S., Bernier, P. P., Bethune, D. S., Meijer, G. \& Salem, J. R. NMR determination of the bond lengths in $\mathrm{C}_{60}$. J. Am. Chem. Soc. 113, 3190-3192 (1991).

41. Hawkins, J. M., Meyer, A., Loren, S. \& Nunlist, R. Statistical incorporation of carbon- $13{ }^{13} \mathrm{C}_{2}$ units into $\mathrm{C}_{60}$ (buckminsterfullerene). J. Am. Chem. Soc. 113, 9394-9395 (1991).

42. Ebbesen, T. W., Tabuchi, J. \& Tanigaki, K. The mechanistics of fullerene formation. Chem. Phys. Lett. 191, 336-338 (1992).

43. Hearne, K. R., Nixon, S. A. \& Whittakers, D. Axial temperature distributions along thin graphite electrodes. J. Phys. D 5, 710-716 (1972).

44. Taylor, P. H. \& Dellinger, B. Pyrolysis and molecular growth of chlorinated hydrocarbons. J. Anal. Appl. Pyrolysis 49, 9-29 (1999).

45. Taylo, P. H. \& Lenoir, D. Chloroaromatic formation in incineration processes. Sci. Total Environ. 269, 1-24 (2001).

46. Hernandez, E., Ordejon, P. \& Terrones, H. Fullerene growth and the role of nonclassical isomers. Phys. Rev. B 63, 193403/193401-193403/193404 (2001).

47. Tan, Y. Z. et al. Chlorofullerenes featuring triple sequentially fused pentagons Nat. Chem. 2, 269-273 (2010).

\section{Acknowledgements}

We thank Professor Yu-Qi Feng from Wuhan University for HPLC support and Professo G. Michael Blackburn from University of Sheffield, UK, for revising the English of the manuscript. This work was supported by the NNSF of China (Grants 21031004, 21021061, 20973137, and 20876127) and the 973 Program [Grants 2007CB815300(1,7) and 2011CB935901]

\section{Author contributions}

S.Y.X., L.S.Z. and R.B.H. conceived and designed the research; Y.Z.T. conducted the isolation and identification and plotted the figures; Z.J.L., R.T.C. and F.Z. participated in the arc-discharge experiments; Jun L. performed the mass/energy conservation equation simulations; X.L. conceived the theoretical work and Jia L. conducted theoretical computations; S.Y.X. and Y.Z.T. analysed the experimental data; S.Y.X., X.L. and Jun L. wrote the paper; All authors discussed the results and commented on the manuscript.

\section{Additional information}

Supplementary Information accompanies this paper at http://www.nature.com/ naturecommunications

Competing financial interests: The authors declare no competing financial interests.

Reprints and permission information is available online at http://npg.nature.com/ reprintsandpermissions/

How to cite this article: Tan Y-Z. et al. Carbon arc production of heptagon-containing fullerene[68]. Nat. Commun. 2:420 doi: 10.1038/ncomms1431 (2011).

License: This work is licensed under a Creative Commons Attribution-NonCommercialShare Alike 3.0 Unported License. To view a copy of this license, visit http:// creativecommons.org/licenses/by-nc-sa/3.0/ 